\title{
Decision making in the partnership
}

\section{Michael Fenton}

Practice Management Consultant, British Dental Association

\section{What is a partnership?}

A partnership is an association of two or more people who work together to manage and run a business. They will need to discuss what their vision is for the business and ensure they can agree on the necessary business decisions to do with the functioning of the business to enable them to make a profit that they can then share. It is best if the parties discuss this beforehand to enable them to put in place a partnership agreement. This will then prove an invaluable resource in settling any disputes in a fair way.

If you have found someone that you work well with and are entering a partnership it is worth discussing how decisions will be made in the partnership. You will both have different experiences and may find that you have different interests in the running of the business. This is a valuable resource and might make the discussion of who is responsible for various choices easier. It is however both your responsibilities and so it is worth careful consideration before agreeing that one or both partners can make decisions without the input of the other.

\section{What decisions do partners need to consider?}

If it has an impact on your business, then you need to agree how decisions will be made.

These decisions can be broken down into 5 main categories:

\section{Employment}

If you are to run a business you need to be able to staff it. This means you will need to consider who is to be working for you, what you will pay them and who will manage them. There will need to be staff appraisals and training will need to be identified and undertaken. There will also inevitably be occasional disciplinary concerns which could lead to dismissal. You may find that one of the partners has a talent or background in human resources in which case it may be a simple case of delegating the role to this partner. However, the other partners will still need to ensure they can work with any potential staff and so it would seem to be sensible to have at least some input into this process.

\section{Materials and equipment}

There will be an ongoing process of monitoring and ordering stock. This may be as simple as re-ordering the staples when they run out but could involve trying new materials to see if new products are better. Who will have the final say on whether the slightly more expensive filling material that sets faster is what you will be using in future? You will also need to consider the equipment you are using in practice. You might not need to see the new set of handpieces being ordered but might want to have a say on installing new radiography equipment to allow you to take OPGs in practice.

\section{Facilities}

If you are moving into an already set up practice you might not need to consider this immediately but the longer the practice is running the more likely there will need to be some refurbishments or maintenance of the premises. Who will decide who gets to update their surgery first while the other has to work with the old dental chair? You might feel the reception area is a little old fashioned and needs modernising especially on the back of the new measures you are having to bring into the practice due to COVID-19.

\section{Product}

You might have already worked together before doing the same work or may have different specialisms. What do you want your practice to offer patients? What services will you offer on the NHS or privately. Where you both offer treatment privately you will need to discuss your charges for patients to ensure your practice is offering a consistent service.

\section{Advertising}

When you have agreed on what service you want to provide to your patients you will then need to consider how you tell them about it. Where you are both providing the same treatments it can be easier to tell patients about it but if one of you has an interest in tooth whitening that the other doesn't they may feel that advertising this won't benefit them.

If you have a clear vision for your practice that aligns with the partners, you may not foresee issues with these decisions. It is still worth discussing these decisions and coming to some agreement on how decisions will be finalised in the practice.

\section{How to make decisions?}

There are three options for making decisions in practice. Unilaterally, by majority and unanimously. By default, decisions in partnerships tend to pass by majority rules. This can work well for decisions that have an impact but won't fundamentally change the business, provided of course there is an odd number of partners or you can end up in a deadlock. There may be some decisions that you are happy for yourself or your partner to make without needing input from the partners such as restocking the basic practice supplies. If you can agree this in advance it can streamline the administration in the business. Finally there are some decisions that will have significant impacts on the business and may be costly or risky to pursue, these will need careful consideration and it would be worth agreeing to only pursue these with the agreement of all involved.

$B D A$ members can access further advice about Partnerships from the BDA advisory services.

https://doi.org/10.1038/s41404-020-0553-y 